Reading a short story changes children's sustainable behavior in a resource dilemma Mirjam Ebersbach \& Ida Brandenburger https://doi.org/10.1016/i.jecp.2019.104743 Accepted Manuscript, Journal of Experimental Child Psychology, Volume 191, 2020 


\begin{abstract}
Fostering sustainable behavior in children and adolescents should be a central aim of today's education. Even though the interplay of factors affecting sustainable behavior is complex, simple interventions can be effective, too. In the present study, 10-year-olds $(N=132)$ were read a short story on two foresters who collectively used a forest to gain timber, facing a resource dilemma that involved striving for maximizing their individual profit while sustaining the forest. In the story, the foresters solved the dilemma in favor of the resource and served therewith as positive role models. Children in the control condition were read a short informative story on urban gardening, not including a dilemma or any moral cues. Before and after the intervention, children played a fishing conflict game to assess their sustainable behavior. Children who were presented with the positive role models played the game after the intervention more sustainably than before. Children in the control condition, in contrast, played it even less sustainably after the intervention. The results suggest that a short intervention might affect children's sustainable behavior.
\end{abstract}

Key words: sustainable behavior; resource dilemma; children; intervention; fishing conflict game 


\section{Reading a short story changes children's sustainable behavior in a resource dilemma}

In order to prevent further ecological damage, it is necessary to act ecologically sustainable and not to exploit slowly regenerating natural resources. This applies even more to children and adolescents who will be the adults of tomorrow. A recent longitudinal study showed that environmental attitudes and behavior already emerge in childhood and undergo systematic changes at least until early adulthood. Interestingly, environmental behavior starts to consolidate in middle childhood while environmental attitudes are still variable (Otto, Evans, Moon, \& Kaiser, 2019). However, the factors that affect human behavior in general and ecologically sustainable behavior in particular - operate in a complex manner (cf. Ajzen, 1991; Gifford \& Nilsson, 2014; Ostrom, 2006; Klöckner, 2013; Steg \& Vlek, 2009; Stern, Dietz, Abel, Guagnano, \& Kalof, 1999). This raises the question of whether a simple intervention can nevertheless change people's ecological behavior. In fact, simple interventions, such as providing signs or short messages as hints, increased adults' frequency of turning out the light when leaving the room (Luyben, 1980), separating waste (Tobias, 2009), engaging in food recycling (Shearer, Gatersleben, Morse, Smyth, \& Hunt, 2017), or reusing towels in hotels (Goldstein, Cialdini, \& Griskevicius, 2008; for overviews, see Abrahamse, Steg, Vlek, \& Rothengatter, 2005; Osbaldiston \& Schott, 2012). Another great example demonstrating that role models, too, can affect environmental attitudes and behavior is Greta Thunberg who initiated a world-wide movement among the youth (i.e., "Fridays for future") to protect the climate (\#FridaysForFuture, 2019). The present study examined whether children's sustainable behavior can be promoted by a simple intervention. We chose a story-based intervention including a short text describing positive role models. Stories are conceived as an appropriate tool in children's environmental education (Altun, 2018).

\section{Short stories and role models to change ecological attitudes and behavior of adults}

So far, short stories have been mainly employed successfully with adults, for instance, to promote their willingness to join carpools (Kearney \& Young, 1995), to save energy (Yates 
\& Aronson, 1983), or to consume organic food (Hoffmann \& Schlicht, 2013). A story-based intervention can impart knowledge, which is an important basis for pro-environmental behavior (e.g., De Young, 1988). In addition, a story-based intervention that includes role models can transport or activate social norms. Social norms can be conceived as code of conduct within social groups (Lapinski \& Rimal, 2005). They represent a significant factor affecting peoples' behavior in general (Ajzen, 1991) and their sustainable behavior in particular (Abrahamse \& Steg 2013; Biel \& Thøgersen, 2007; Ostrom, 1990). Two kinds of social norms can be distinguished: Descriptive social norms that include a behavior shown by the majority of people while injunctive social norms that refer to behavior that is dis- or approved by the majority of people (Cialdini, Kallgren, \& Reno, 1991). Introducing role models by means of a story (e.g., figures that act in a particular situation in a sustainable manner) can transport and activate both kinds of social norms by demonstrating the target behavior (Bandura, 1977), and by indirectly representing what is expected by others. Beyond activating social norms, role models can represent a positive goal and, at the same time, show a way how to achieve this goal, therewith guiding behavior (Lockwood \& Kunda, 1997, 1999).

Most of the studies so far that used role models to promote pro-environmental behavior were conducted with adults (for reviews, see Dwyer, Leeming, Cobern, Porter, \& Jackson, 1993; Osbaldiston \& Schott, 2012). For instance, students who had lunch in a cafeteria observed two role models arguing about waste separation and thereafter disposing their waste in separate containers. Observing these models increased students' waste separation rate significantly immediately and five days after the intervention (Sussman, Greeno, Gifford, \& Scannell, 2013). A similar effect of positive modelling was revealed for saving water when soaping up under the shower (Aronson \& O'Leary, 1982), or for switching out the light when leaving the washroom (Oceja \& Berenguer, 2009). Correspondingly, active environmentalists reported in interviews that role models had a significant influence on 
developing their own pro-environmental attitudes and behavior (Chawla, 1999). However, role models can also have negative effects. For instance, knowing the intense energy consumption of neighbors can affect peoples' own energy consumption behavior negatively and to a stronger degree than their own attitudes towards energy conservation (Schultz, Nolan, Cialdini, Goldstein, \& Griskevicius, 2007; see also Richter, Thøgersen, \& Klöckner, 2018, for such a "boomerang effect" on shopping non-/sustainable seafood after being presented with descriptive social norms).

\section{Role models of children}

With regard to children, parents usually serve as primary role models and have a significant impact on their children's pro-environmental attitudes and behavior (e.g., Grønhøj \& Thøgersen, 2009, 2012, 2017). For instance, a longitudinal study demonstrated that the environmental attitudes of mothers predict the environmental behavior of their children as young adults (Evans, Otto, \& Kaiser, 2018). Ando, Yorifuji, Ohnuma, Matthies, and Kanbara (2015) found that parents affected their children's waste handling behavior both directly by serving as role models and indirectly by constituting an injunctive social norm (i.e., children perceived their parents as expecting a certain behavior from them). The authors concluded that parents showing pro-environmental behavior in everyday life are the most effective way to promote this behavior in their children, being more effectively than just communicating. Even young children tend to orient their behavior towards other persons: Five-year-olds acted in a task requiring common coordination in line with the behavior of the majority of other children that they observed (Grueneisen, Wyman, \& Tomasello, 2015). However, as parents' behavior cannot always be observed by the children, parents' active communication can also positively affect children's recycling and re-use behavior, for instance (Matthies, Selge, \& Klöckner, 2012).

\section{Interventions to change ecological attitudes and behavior of children and adolescents}


Intervention studies that aim at changing the ecological attitudes and behavior of children and adolescents are still rare and often included poor methodologies (see Zelezny, 1999, for a meta-analysis). For instance, correlations were interpreted as causal effects (e.g., Eagles \& Demare, 1999). This is a clear shortcoming as children and adults will not only make environmentally relevant decisions in the future but they can also affect the environment-related knowledge and behavior of their parents and others (Damerell, Howe, \& Milner-Gulland, 2013; Vaughan, Gack, Solorazano, \& Raym, 2003).

Studies so far mostly examined the effects of children's and adolescents' experiences with nature (e.g., Broom, 2017; Hosaka, Sugimoto, \& Numata, 2017; for a review, see Gill, 2014). Wilderness expeditions, for instance, can enhance adolescents' connectedness with and attitude towards nature (Barton, Bragg, Pretty, Roberts, \& Wood, 2016), which strengthens in turn the intention to act pro-environmentally (e.g., Cheng \& Monroe, 2010). In addition, more structured environmental education programs, often including a variety of outdoor activities (e.g., hiking, encountering animals, visiting field centers) can enhance children's environmental knowledge and their connectedness to nature (Liefländer, Fröhlich, Bogner, \& Schultz, 2013). The effect of such education programs is larger for younger children (Liefländer \& Bogner, 2014). However, environmental programs included in curricula did, in the past, not always address all relevant predictors related to the sustainable behavior of pupils and were therefor not always effective (for a review, see Boerschig \& de Young, 1993). A more recent review found that environmental education programs can yield positive effects on the environmental literacy of school-children, in particular when published curricula on environmental education were combined with time spent outdoors (Stevenson, Peterson, Bondell, Mertig, \& Moore, 2013). It has furthermore been reported that sustainable school buildings are associated with more positive environment-related attitudes and behavior of the school children, even after controlling for socioeconomic factors (Tucker \& Izadpanahi, 2017). 
With regard to easy to implement and yet effective interventions, there is much less research with children and adolescents. One study showed that a one-day intervention involving learning units on climate change can have positive effects on adolescents' environmental attitudes by reducing their utilitarian approach to nature also in the long run (Sellmann \& Bogner, 2013). Another study found that placing emoticons on waste bins enhanced children's and adults' recycling behavior (Meng \& Trudel, 2017). By the present study, we strive at filling this gap by testing the effect of another simple intervention (i.e., a short story including positive role models) on children's sustainable behavior.

\section{Paradigms to assess ecologically sustainable behavior}

One method to investigate ecologically sustainable behavior experimentally is based on the commons dilemma or resource dilemma (Hardin, 1968). Here, a natural, slowly regenerating resource - such as a forest or a lake - is used by multiple harvesters (i.e., players). They face a dilemma between maximizing their own profit and maintaining the resource for using it in the long run. Typically, the resource is in danger when harvesters do not cooperate but exploit the resource, and / or when the number of harvesters increases (e.g., the world's population) - which is also referred to as the tragedy of the commons (Hardin, 1968). One paradigm involving such a resource dilemma is the fishing conflict game (Spada \& Opwis, 1985), which has often been employed to examine adults' sustainable behavior (e.g., Nerb, Spada, \& Ernst, 1997; Spada, Opwis, Donnen, Schwiersch, \& Ernst, 1987). In the original version of this game, three players are supposed to be fishers who jointly use a lake. They do not know how much fish is in the lake at the beginning and they are not informed about how many rounds (i.e., fishing seasons) they will play. The regeneration of the fish population across rounds follows a biological growth function that is not easy to figure out. In each round, the players have to decide individually how much fish they intend to catch (maximum: 25\%). These quantities are added up and announced, together with information concerning the remaining quantity of fish in the current round and the quantity of fish at the 
beginning of the new round. Indicators of ecologically sustainable behavior in this game include the quantity of caught fish, the replenished quantity of fish per round, and the remaining quantity of fish in the lake after the game is over.

A related, but simpler game is the nuts game, which is also suitable for children (Edney, 1979). In the nuts game, a group of players is presented with a bowl containing twelve nuts in the beginning. The players are allowed to take as many nuts as they want to, which can be converted into rewards at the end of the game. In addition, players are informed that the remaining quantity of nuts in the bowl will be doubled after a fixed period of time. In a pilot study with college students, the resource was exhausted already in the first round in $65 \%$ of the games (Edney, 1979). Gifford (1982) played this game with 3- to 16-year-olds and found no such disastrous behavior. Instead, the cooperative and therewith sustainable behavior increased with age: While among 3-year-olds only $11 \%$ kept the resource alive, this rate increased rather continuously up to $88 \%$ in 14-year-olds.

The paradigm used in the present study to assess children's sustainable behavior is a compound of the fishing conflict game and the nuts game. This version was already employed to investigate ecological behavior in primary school children (Ebersbach, Malkus, \& Ernst, 2019). In this study, 6- to 11-year-old children acted - similar as adults - more sustainably when the quantity of the catch was limited, when they played the game alone and not in a group, and when they were allowed to communicate in the group. In addition, older children acted more sustainably than younger children. Koomen and Herrmann (2018) played another commons dilemma involving a water resource with 6-year-olds. They found, like Ebersbach et al. (2019), that children acted more sustainable when they acted individually than when they acted as a pair of two. Children also showed a learning effect when playing repeatedly with the same partner by cooperating more successfully. They also developed verbal and behavioral strategies to aligning their consumption, and to support their (self-)distraction in the waiting periods. This lead to a considerable rate of success in the dilemma. 
The aim of the present study was to test whether a simple intervention, including the reading of a short story comprising two foresters as positive role models (i.e., experimental condition), enhances children's sustainable behavior in the frame of a fishing conflict game. As the mere experience with resource dilemmas can improve sustainable behavior (e.g., Cass \& Edney, 1978), we realized an experimental pre-post design with a control condition, in which children read a short story on urban gardening. We expected a larger increase of sustainable behavior from pre- to post-test in the experimental condition compared to the control condition.

\section{Method}

\section{Design}

This study followed a 2 (intervention: positive role models vs. control condition between-subjects factor) x 2 (time: before vs. after the intervention - within-subjects factor) design. Sustainability served as dependent variable. As children played the resource dilemma game in groups, performance was analyzed on group level. The indicators for sustainability of the group performance were adopted from Hine and Gifford (1996), including (1) the number of played rounds before the resource was extinguished (i.e., rounds: max. 5), (2) the total number of fish replenished across all played rounds (i.e., replenishment), and (3) the final number of fish that remained in the lake after the game was finished (i.e., final stock) ${ }^{1}$. Descriptive statistics for these indicators is shown in Table 1. These measures were significantly correlated with each other in each condition ( $r$ s ranging between .29 and .80 ; see Appendix A). In order to generate a general index of sustainability in the groups, these measures were z-transformed and added up (Gifford, 1982).

\footnotetext{
${ }^{1}$ Please note that the final number of fish was 0 when the resource was extinguished before the fifth round.
} 
Table 1

Descriptive statistics of the sustainability measures (not standardized)

\begin{tabular}{lcccc}
\hline & \multicolumn{4}{c}{ Intervention } \\
\cline { 2 - 5 } & \multicolumn{3}{c}{ Role model } & \multicolumn{2}{c}{ Control } \\
\cline { 2 - 5 } Sustainability & Before & After & After \\
measure & $4.2(1.4)$ & $4.8(0.5)$ & $4.7(0.7)$ & $4.3(1.1)$ \\
Rounds & $54.3(37.7)$ & $61.4(33.7)$ & $64.1(28.9)$ & $42.7(28.1)$ \\
Replenishment & $54.5(16.0)$ & $20.5(21.0)$ & $17.2(17.2)$ & $8.6(15.2)$ \\
Final Stock & $12.1(16.0)$ & & & \\
\hline
\end{tabular}

\section{Participants}

Participants were 132 fifth-graders (67 male, 65 female, mean age: $M=10.81$ years, $S D=0.63$ ). This age group was selected as a developmental shift takes place between primary and secondary school age from seeing nature primarily as serving humans towards feeling responsible for nature (Kahn, 1999) and as environmental behavior starts to consolidate around the age of 10 years (Otto et al., 2019). Half of the children was randomly assigned to each condition.

\section{Procedure}

Children attended the experimental session in groups of three. Each group consisted of two randomly allotted children and the experimenter as third player, who continuously played with a cooperative / sustainable strategy by always taking $1 / 6$ of the current fish stock. After being seated, the children were informed that all data collected during the experiment would be treated confidentially, and that they were free to terminate their participation without any explanation and without consequences at any time. Then the experimenter explained the rules of the game, which was based on the fishing conflict game by (Spada \& Opwis, 1985), but 
was reduced in its complexity. It included an initial stock size of 60 fish (which was also the maximum that could never be exceeded during the whole game) and a regeneration rate of $100 \%$ of the remaining fish stock after each round.

The children were told that they should imagine to be fishermen who would harvest fish from the lake over multiple seasons. During each season (i.e., rounds of the experiment) the players should decide simultaneously and in a covert manner how many fish to harvest. Thus, each child should write down the intended quantity of fish to be harvested on a piece of paper and provide it to the experimenter, who then calculated the new stock size of the next season and announced it to the players. The quantity of fish in the lake for the next round was adjusted accordingly. Importantly, the players were not informed about the harvesting behavior of the other players throughout the game. To enhance the validity of the game and to increase the personal value of the resource, children could exchange their caught fish into candy at the end of the game (Alencar, Oliveira Siqueira \&Yamamoto, 2008). Like in many other studies involving resource dilemmas, communication among the players was not permitted during or between the fishing seasons (Allison \& Messick, 1985; Bell, Petersen \& Hautaluoma, 1989). Furthermore, only information about the initial stock size and the regeneration rate were given but not about the number of rounds to be played, the maximum catch, the optimal harvest strategy, or the fishing behavior of the other players. Prior to the simulation, a practice round was run for each group to ensure that every child understood the procedure of the game, and clarification was provided if necessary. A game could last maximally across five seasons - or less if the resource was distinguished earlier.

The first game was followed by the manipulation of role model behavior. Therefore, a short story about two foresters facing a resource dilemma between striving for their individual profit and sustaining the forest, was read out loud to the participants of the experimental condition. By making compromises, the foresters were able to preserve the resource and thereby served as positive role models. Participants of the control condition read a short 
informative story on urban gardening, not including a dilemma or any moral cues (for both stories, see Appendix B). The story in the experimental condition included both descriptive norms (i.e., what the foresters do) and injunctive norms (i.e., that their behavior - after they decided to cooperate - is desirable; Cialdini, 2003). The story in the control condition only included descriptive norms (i.e., that people engage in urban gardening) but no moral evaluation. Both stories referred to nature to make them comparable. According to Cialdini (2003), only the combination of both norms leads to the intended effects.

To ensure children's attentiveness during the manipulation, a control question was posed after the story was read (i.e., role model group: "Why was the forest not completely exhausted?"; control group: “Why are people interested in urban gardening?"). Two children needed to be excluded because they could not answer the question correctly. The other ones continued with the second game following the same rules as the first one. After exchanging the harvested fish into candy at the end of the second game, the children were fully debriefed and thanked for their participation.

\section{Results}

To test our hypothesis that modelling a positive, pro-environmental behavior changes the sustainable behavior in a resource dilemma, and that this effect cannot solely be attributed to a mere effect of repeated experience with the dilemma, a 2 (intervention: role model vs. control condition) x 2 (time: before vs. after the intervention) ANOVA with repeated measures was computed, with the group sustainability index as dependent variable. It revealed no main effects of time, $p=.41$, or intervention, $p=.36$, but a significant interaction of these two variables, $F(1,130)=54.18, p<.001, \eta_{\mathrm{p}}{ }^{2}=.29$. Post-hoc tests, computed separately for each intervention condition and corrected for multiple comparisons, revealed a significant increase of the sustainability index in children who were presented with a story including positive role models, $t(65)=-4.29, p=.002, d=.54$, while there was a significant decrease of 
the sustainability index in children who were presented with a story on urban gardening, $t(65)$ $=7.46, p=.002, d=.61($ see Fig. 1$) .^{2}$

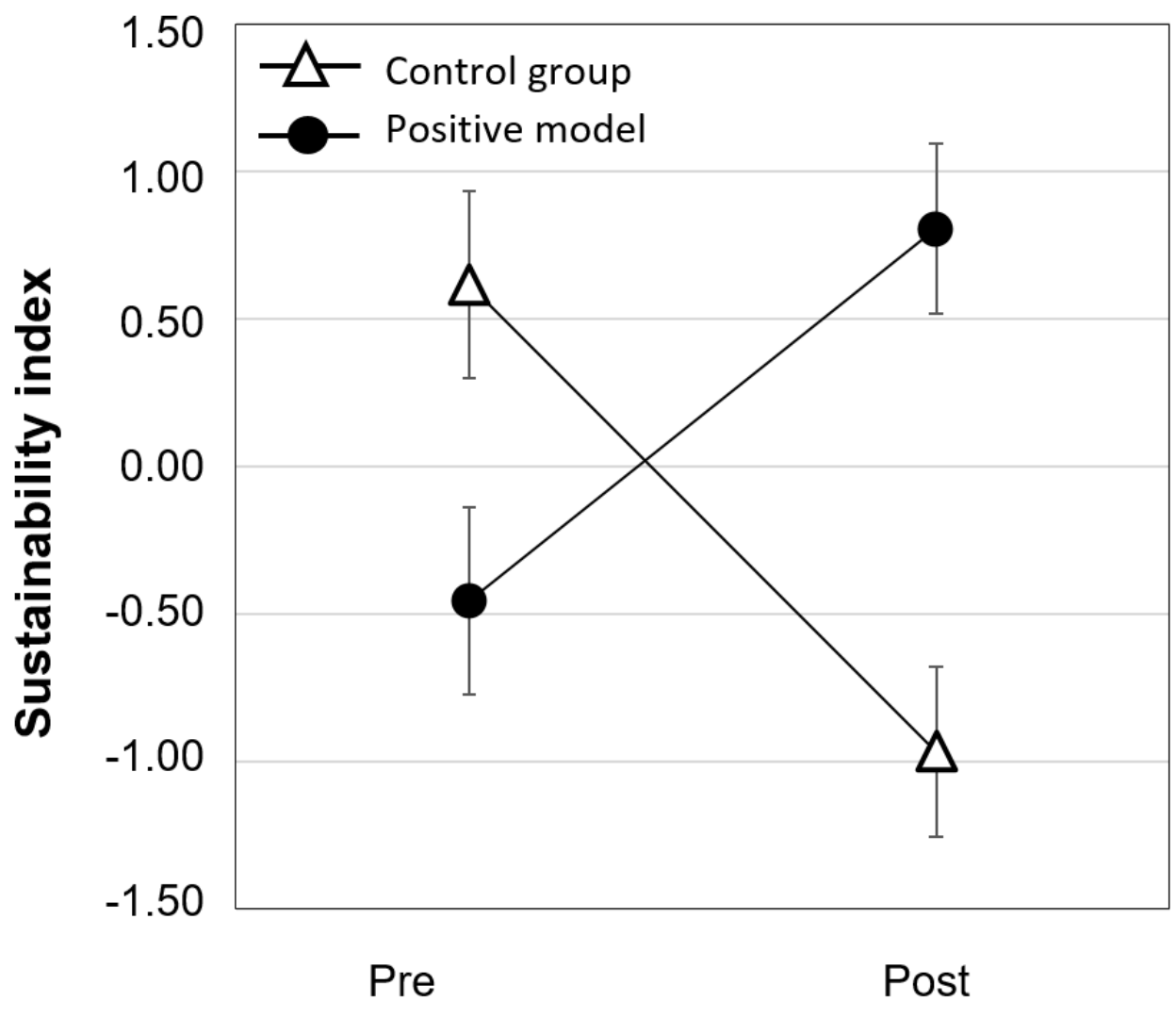

Time

Figure. 1. Mean group sustainability index (i.e., sum of the $z$-transformed sustainability measures) before (pre) and after the intervention (post) including the positive role model or the control condition.

\footnotetext{
2 These results were replicated by using an individual sustainability index as dependent variable, computed as the mean proportion of the initial resource taken by a single player in each round (Hine \& Gifford, 1996), with $F \mathrm{~s}<1$ for the main effects of intervention and time, but a significant interaction between the two variables $F(1,130)=18.10, p<.001, \eta_{\mathrm{p}}{ }^{2}=.12$. However, the group sustainability index is preferable because the behavior of children playing in a group is not independent from each other.
} 
Given the rather unexpected finding that the sustainability index differed already before the intervention between control and experimental group, but in the opposite direction than the final results (i.e., the control group scored lower than the experimental group), we additionally run a control analysis. Therefore, pairs of children were identified, one of the control group and one of the experimental group, who scored similarly concerning their sustainability index in the pre-test (i.e., max. 0.3 points deviation concerning the sustainability index scale ranging from -5.0 to 5.0). This selection resulted in $n=43$ children per group and a similar sustainability index in both groups (control: $M=0.43, S D=1.85$; role model: $M=$ $0.42, S D=1.85), p=.99$. Based on these matched samples, the same repeated measures ANOVA as before was calculated (see Figure 2), revealing a main effect of intervention, $F(1$, $84)=6.21, p=.015, \eta_{\mathrm{p}}{ }^{2}=.07$, and a significant interaction of time and intervention, $F(1,84)$ $=27.7, p<.001, \eta_{\mathrm{p}}{ }^{2}=.25$. Post-hoc tests per intervention condition (Bonferroni-Holm corrected) confirmed for the role model group a significant increase of sustainability index from pre-test to post-test $\left(M_{\text {diff }}=0.74, S D_{\text {diff }}=1.91\right), t(42)=-2.54, p=.015, d=.35$, while the sustainability index in the control group significantly decreased from pre-test to post-test $\left(M_{\text {diff }}=-1.34, S D_{\text {diff }}=1.75\right), t(42)=5.02, p=.002, d=.59$. The additional analyses thus confirmed that the advantage of the role model group over the control group in the post-test thus cannot solely be assigned to pre-test differences. 


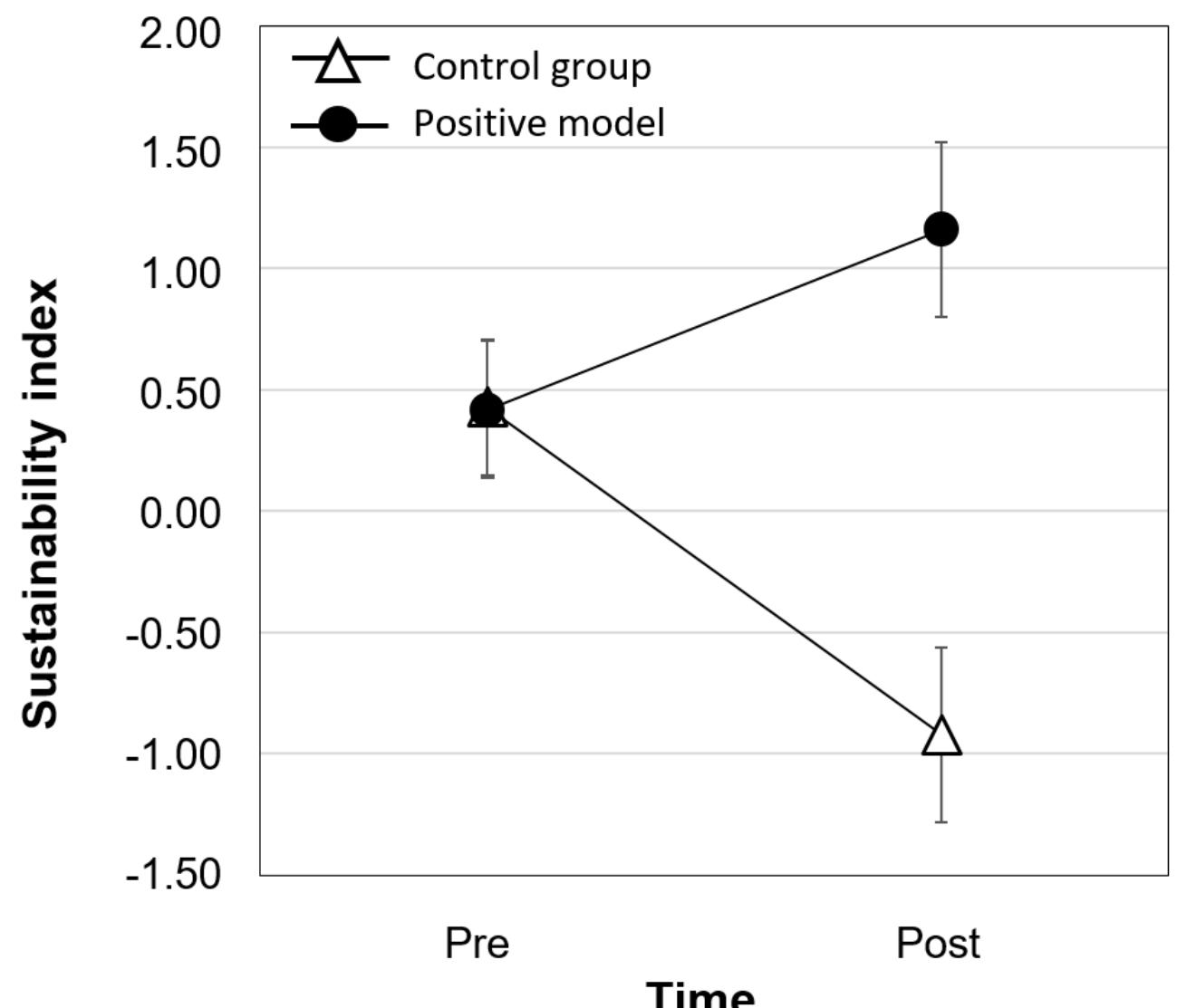

Figure. 2. Mean group sustainability index (i.e., sum of the z-transformed sustainability measures) before (pre) and after the intervention (lost) including the positive role model or the control condition - for matched pairs only (i.e., 43 children per intervention condition).

\section{Discussion}

The aim this study was to test whether a short intervention, including positive role models, would affect children's sustainable behavior in a fishing conflict game. In fact, children acted more sustainably after being read a short story about two foresters who solved a socio-ecological dilemma between maximizing their individual profit and maintaining the forest. Children in the control condition who were read a short story on urban gardening became even more exploiting in the fishing conflict game after the reading. These patterns were confirmed by an additional control analysis based on matched pairs with similar scores before the intervention. The findings suggest that even a short intervention might affect children's sustainable behavior at least in the short run. 
The presentation of positive role models might have activated descriptive and injunctive social norms in terms of showing what others do when facing a dilemma and, by that, indirectly also which behavior might be expected by others (Cialdini, 2003). In addition, the story actually modelled the desirable behavior in the dilemma. To ensure that the effect of the intervention in the present study could only not only be attributed to playing the game a second time but to reading the story on the resource dilemma, a control condition was realized, confirming that only encountering positive role models in the experimental condition yielded a positive effect on children's sustainable behavior. These results are also in line with findings related to the moral development, which can be promoted by being faced with and discussing moral dilemmas (e.g., Berkowitz \& Gibbs, 1983).

Rather unexpected was the negative effect in the control condition in the present study, where children were read a short story on urban gardening. This content was chosen to address nature, too, but without introducing a dilemma or providing any moral hints. Originally, we expected no change of sustainable behavior in this group or even a slight increase due to the repeated playing of the game. However, the negative trend was confirmed by a control analysis that only included children who scored similarly as children in the intervention group before the intervention took place. It is thus no effect of initial differences between the two groups that levelled each other out. One might speculate that the story on urban gardening promoted the idea to exploit nature by vividly demonstrating that even small places in the city can serve for growing plants, and that children transposed this insight to their behavior in the fishing conflict game. However, this assumption needs further examination. Alternatively, children in the control group might have learned in the first game how many rounds the game includes, which is a good basis for developing a strategy that allows to maximize one's own gain before the game is over. If there were several children who have pursued such a competitive strategy - in particular as children in the control group did not encounter positive role models in the intervention - these competitively playing 
children might have served as negative role models, motivating the other children to follow this strategy. In fact, individuals tend to orient their own behavior in commons dilemmas on the (cooperative or competitive) behavior of others (e.g., Brucks, Reips, \& Ryf, 2007; Fleishman, 1988). Moreover, Brucks and Van Lange (2007) showed that even prosocial individuals tend to behave egoistically in a commons dilemma when the resource minimizes. Unfortunately, we cannot identify these mechanisms based on our data as children always played in groups and one can only speculate about the dynamics within the groups.

Even though this study revealed interesting findings, it has some limitations. First, only short-term effects were investigated. It would be interesting to investigate whether the role model intervention would enhance children's sustainable behavior in the long run, too. One could also argue at this point that children had simply learned how to act sustainably and still to make profit throughout the games by observing other children who acted in line with the role models. Thus, the effect of positive role models would just be a generic learning effect, no effect of moral or social norms. However, children passed on information concerning their intended harvest rate covertly to the experimenter and the experimenter, too, harvested in a hidden manner, so that the other child in each group did not know how much the other two players had harvested. They only saw the result after each round. Therefore, a simple effect of strategy adoption seems improbable, while it would emerge under conditions in which the players are informed about the decisions of their co-players in real-time (cf. Goren, Rapoport, \& Kurzban, 2004). Another issue regarding the validity of the findings is that it would be worthwhile to test effects of a role model intervention not only in the context of a commons dilemma but also to test whether it generates to real life contexts. We tried to enhance the validity of the game by individual rewards for the quantity of caught fish of each child. Even if a commons dilemma represents a simplified version of real-world problems, it includes the main structure (i.e., a dilemma between individual and collective interests) that generalize to other contexts, such as the consumption of energy, trees, water, or other animals 
(Gifford, 2012; see also Van Vugt, 2009). Furthermore, there are indicators that these dilemmas are externally valid. This was reported, for instance, in study on the management of a common forest in Africa, assessing both the foresters' behavior in a public goods game and in a field setting (Rustagi, Engel, \& Kosfeld, 2010; see also van Vugt, 2001).

Second, although randomly assigned, children in the control and intervention condition differed concerning their sustainability already in the first game. However, this initial difference was reversed, compared to the difference in the second game: Before the intervention, children in the experimental group acted even less sustainably than children in the control condition. It can only be hypothesized that, by chance, there were initially more non-cooperative children in the experimental condition. The more astonishing is the positive effect of the role model intervention, which was confirmed by running an additional analysis based on matched samples. In future studies, it might be better to assign children according to their sustainable behavior before the intervention comparably to the experimental and control condition. Last but not least, it might be worthwhile to investigate whether the effect of positive role models can be transferred to children's dealing with ecological resources in everyday life to account for the validity of the effect (e.g., Sussman et al., 2013).

To sum up, this study provides first evidence that a short written intervention, in which children encounter the solution of a resource dilemma by positive role models, might enhance their own sustainable behavior in a related resource dilemma. Future research including experimental manipulations is needed to replicate and generalize the present findings and to identify further effective interventions that promote children's pro-environmental behavior. 


\section{References}

Abrahamse, W., \& Steg, L. (2013). Social influence approaches to encourage resource conservation: A meta-analysis. Global Environmental Change, 23(6), 1773-1785. doi:10.1016/j.gloenvcha.2013.07.029

Abrahamse, W., Steg, L., Vlek, C., \& Rothengatter, T. (2005). A review of intervention studies aimed at household energy conservation. Journal of Environmental Psychology, 25(3), 273-291. doi:10.1016/j.jenvp.2005.08.002

Ajzen, I. (1991). The theory of planned behavior. Organizational Behavior and Human Decision Processes, 50(2), 179-211. doi:10.1016/0749-5978(91)90020-T

Alencar, A. I., Oliviera Siqueira, J. de, \& Yamamoto, M. (2008). Does group size matter? Cheating and cooperation in Brazilian school children. Evolution and Human Behavior, 29(1), 42-48. doi:10.1016/j.evolhumbehav.2007.09.001

Allison, S. T., \& Messick, D. M. (1985). The group attribution error. Journal of Experimental Social Psychology, 21, 563-579. doi: 10.1016/0022-1031(85)90025-3

Altun, D. (2018). Preschoolers' pro-environmental orientations and theory of mind: Ecocentrism and anthropocentrism in ecological dilemmas. Early Child Development and Care, 32(3), 1-13. doi:10.1080/03004430.2018.1542385

Ando, K., Yorifuji, K., Ohnuma, S., Matthies, E., \& Kanbara, A. (2015). Transmitting proenvironmental behaviours to the next generation: A comparison between Germany and Japan. Asian Journal of Social Psychology, 18(2), 134-144. doi:10.1111/ajsp.12078

Aronson, E., \& O’Leary, M. (1982). The relative effectiveness of models and prompts on energy conservation: A field experiment in a shower room. Journal of Environmental Systems, 12(3), 219-224. doi:10.2190/ubd5-4y9b-61ef-wum6

Bandura, A. (1977). Social Learning Theory. Upper Saddle River: Prentice-Hall.

Barton, J., Bragg, R., Pretty, J., Roberts, J., \& Wood, C. (2016). The wilderness expedition: an effective life course intervention to improve young people's well-being and 
connectedness to nature. Journal of Experiential Education, 39(1), 59-72. doi:10.1177/1053825915626933

Bell, P. A., Petersen, T. R., \& Hautaluoma, J. E. (1989). The effect of punishment probability on overconsumption and stealing in a simulated commons. Journal of Applied Social Psychology, 19, 1483-1495. doi: 10.1111/j.1559-1816.1989.tb01460.x.

Berkowitz, M. W., \& Gibbs, J. C. (1983). Measuring the developmental features of moral discussion. Merril-Palmer Quarterly, 29, 399-410.

Biel, A., \& Thøgersen, J. (2007). Activation of social norms in social dilemmas: A review of the evidence and reflections on the implications for environmental behaviour. Journal of Economic Psychology, 28(1), 93-112. doi:10.1016/j.joep.2006.03.003

Boerschig, S., \& de Young, R. (1993). Evaluation of selected recycling curricula: Educating the green citizen. The Journal of Environmental Education, 24(3), 17-22. doi:10.1080/00958964.1993.9943498

Broom, C. (2017). exploring the relations between childhood experiences in nature and young adults' environmental attitudes and behaviours. Australian Journal of Environmental Education, 33(01), 34-47. doi:10.1017/aee.2017.1

Brucks, W., Reips, U. D., \& Ryf, B. (2007). Group norms, physical distance, and ecological efficiency in common pool resource management. Social Influence, 2, 112-135. doi:10.5167/UZH-19634

Brucks, W. M., \& van Lange, P. A. M. (2007). When prosocials act like proselfs in a commons dilemma. Personality \& Social Psychology Bulletin, 33(5), 750-758. doi:10.1177/0146167206298569

Cass, R. C., \& Edney, J. J. (1978). The commons dilemma: A simulation testing the effects of resource visibility and territorial division. Human Ecology, 6, 371-386. 
Chawla, L. (1999). Life paths into effective environmental action. The Journal of Environmental Education, 31(1), 15-26. doi:10.1080/00958969909598628

Cheng, J. C.-H., \& Monroe, M. C. (2010). Connection to nature: Children's affective attitude toward nature. Environment and Behavior, 44(1), 31-49. doi:10.1177/0013916510385082

Cialdini, R. B. (2003). Crafting normative messages to protect the environment. Current Directions in Psychological Science, 12(4), 105-109. doi:10.1111/1467-8721.01242

Cialdini, R. B., Kallgren, C. A., \& Reno, R. R. (1991). A Focus Theory of Normative Conduct: A theoretical refinement of the role of norms in human behavior. Advances in Experimental Social Psychology, 24, 201-234.

Damerell, P., Howe, C., \& Milner-Gulland, E. J. (2013). Child-orientated environmental education influences adult knowledge and household behaviour. Environmental Research Letters, 8(1), 15016. doi:10.1088/1748-9326/8/1/015016

De Young, R. (1988). Exploring the difference between recyclers and non-recyclers: The role of information. Journal of Environmental Systems, 18(4), 341-351. doi:10.2190/fbqc5v5d-hhvc-v6x8

Dwyer, W. O., Leeming, F. C., Cobern, M. K., Porter, B. E., \& Jackson, J. M. (1993). Critical review of behavioral interventions to preserve the environment. Environment and Behavior, 25(5), 275-321. doi:10.1177/0013916593255001

Eagles, P. F. J., \& Demare, R. (1999). Factors influencing children's environmental attitudes. The Journal of Environmental Education, 30(4), 33-37. doi:10.1080/00958969909601882

Ebersbach, M., Malkus, D., \& Ernst, A. (2019). Factors that affect primary-school children's sustainable behavior in a resource dilemma. Journal of Experimental Child Psychology, 184, 18-33. doi: 10.1016/j.jecp.2019.03.007 
Edney, J. J. (1979). The nuts game: A concise commons dilemma analog. Environmental psychology and nonverbal behavior, 3(4), 252-254.

Evans, G. W., Otto, S., \& Kaiser, F. G. (2018). Childhood origins of young adult environmental behavior. Psychological Science, 29(5), 679-687. doi:10.1177/0956797617741894

Fleishman, J. A. (1988). The effects of decision framing and others' behavior on cooperation in a social dilemma. Journal of Conflict Resolution, 32, 162-180. doi:10.1177/0022002788032001008

Gifford, R. (1982). Children and the commons dilemma. Journal of Applied Social Psychology, 12, 269-280.

Gifford R. (2012). Applying Social Psychology to the Environment. In F. W. Schneider, Applied Social Psychology: Understanding and Addressing Social and Practical Problems (pp. 297-322). Los Angeles: Sage.

Gifford, R., \& Nilsson, A. (2014). Personal and social factors that influence proenvironmental concern and behaviour: A review. International Journal of Psychology, 49(3), 141-157. doi:10.1002/ijop.12034

Gill, T. (2014). The benefits of children's engagement with nature: A systematic literature review. Children, Youth and Environments, 24, 10-34.

Goldstein, N. J., Cialdini, R. B., \& Griskevicius, V. (2008). A room with a viewpoint: Using social norms to motivate environmental conservation in hotels. Journal of Consumer Research, 35(3), 472-482. doi:10.1086/586910

Goren, H., Rapoport, A., \& Kurzban, R. (2004). Revocable commitments to public goods provision under the real-time protocol of play. Journal of Behavioral Decision Making, 17, 17-37. doi: 10.1002/bdm.455 
Grønhøj, A., \& Thøgersen, J. (2009). Like father, like son? Intergenerational transmission of values, attitudes, and behaviours in the environmental domain. Journal of Environmental Psychology, 29(4), 414-421. doi:10.1016/j.jenvp.2009.05.002

Grønhøj, A., \& Thøgersen, J. (2012). Action speaks louder than words: The effect of personal attitudes and family norms on adolescents' pro-environmental behaviour. Journal of Economic Psychology, 33(1), 292-302. doi:10.1016/j.joep.2011.10.001

Grønhøj, A., \& Thøgersen, J. (2017). Why young people do things for the environment: The role of parenting for adolescents' motivation to engage in pro-environmental behaviour. Journal of Environmental Psychology, 54, 11-19. doi:10.1016/j.jenvp.2017.09.005

Grueneisen, S., \& Tomasello, M. (2017). Children coordinate in a recurrent social dilemma by taking turns and along dominance asymmetries. Developmental Psychology, 53(2), 265273. doi: $10.1037 / \operatorname{dev} 0000236$

Hardin, G. (1968). The tragedy of the commons. Science, 162, 1243-1248.

Hine, D. W., \& Gifford, R. (1996). individual restraint and group efficiency in commons dilemmas: The effects of two types of environmental uncertainty. Journal of Applied Social Psychology, 26(11), 993-1009. doi:10.1111/j.1559-1816.1996.tb01121.x

Hoffmann, S., \& Schlicht, J. (2013). The impact of different types of concernment on the consumption of organic food. International Journal of Consumer Studies, 37(6), 625633. doi:10.1111/ijcs.12044

Hosaka, T., Sugimoto, K., \& Numata, S. (2017). Childhood experience of nature influences the willingness to coexist with biodiversity in cities. Palgrave Communications, 3 , 17071. doi:10.1057/palcomms.2017.71

Kahn, P. H. (1999). The human relationship with nature: Development and culture. Cambridge: MIT Press. 
Kearney, A. R., \& Young, R. de. (1995). A knowledge-based intervention for promoting carpooling. Environment and Behavior, 27, 650-678.

Klöckner, C. A. (2013). A comprehensive model of the psychology of environmental behaviour - A meta-analysis. Global Environmental Change, 23(5), 1028-1038. doi:10.1016/j.gloenvcha.2013.05.014

Koomen, R., \& Herrmann, E. (2018). An investigation of children's strategies for overcoming the tragedy of the commons. Nature: Human Behaviour, 162, 1243. doi:10.1038/s41562-018-0327-2

Lapinski, M. K., \& Rimal, R. N. (2005). An explication of social norms. Communication Theory, 15, 127-147.

Liefländer, A. K., \& Bogner, F. X. (2014). The effects of children's age and sex on acquiring pro-environmental attitudes through environmental education. The Journal of Environmental Education, 45(2), 105-117. doi:10.1080/00958964.2013.875511

Liefländer, A. K., Fröhlich, G., Bogner, F. X., \& Schultz, P. W. (2013). Promoting connectedness with nature through environmental education. Environmental Education Research, 19(3), 370-384. doi:10.1080/13504622.2012.697545

Lockwood, P., \& Kunda, Z. (1997). Superstars and me: Predicting the impact of role models on the self. Journal of Personality and Social Psychology, 73, 91-103.

Lockwood, P., \& Kunda, Z. (1999). Salience of best selves undermines inspiration by outstanding role models. Journal of Personality and Social Psychology, 76, 214-228.

Luyben, P. D. (1980). Effects of informational prompts on energy conservation in college classrooms. Journal of Applied Behavior Analysis, 13(4), 611-617. doi:10.1901/jaba.1980.13-611

Matthies, E., Selge, S., \& Klöckner, C. A. (2012). The role of parental behaviour for the development of behaviour specific environmental norms - The example of recycling 
and re-use behaviour. Journal of Environmental Psychology, 32(3), 277-284.

doi:10.1016/j.jenvp.2012.04.003

Meng, M. D., \& Trudel, R. (2017). Using emoticons to encourage students to recycle. The Journal of Environmental Education, 48(3), 196-204. doi:10.1080/00958964.2017.1281212

Nerb, J., Spada, H., \& Ernst, A. (1997). A cognitive model of agents in a commons dilemma. Proceedings of the Nineteenth Annual Conference of the Cognitive Science Society (pp. 560-565). Mahwah, NJ: Lawrence.

Nolan, J. M., Schultz, P. W., Cialdini, R. B., Goldstein, N. J., \& Griskevicius, V. (2008). Normative social influence is underdetected. Personality and Social Psychology Bulletin, 34(7), 913-923. doi:10.1177/0146167208316691

Oceja, L., \& Berenguer, J. (2009). Putting text in context: The conflict between pro-ecological messages and anti-ecological descriptive Norms. Spanish Journal of Psychology, 12, $657-666$.

Osbaldiston, R., \& Schott, J. P. (2012). Environmental sustainability and behavioral science. Environment and Behavior, 44(2), 257-299. doi:10.1177/0013916511402673

Ostrom, E. (1990). Governung the commons: The evolution of institutions for collective action. New York: Cambridge University Press.

Ostrom, E. (2006). The value-added of laboratory experiments for the study of institutions and common-pool resources. Journal of Economic Behavior and Organization, 61, 149-163. doi: 10.1016/j.jebo.2005.02.008

Otto, S., Evans, G. W., Moon, M. J., \& Kaiser, F. G. (2019). The development of children's environmental attitude and behavior. Global Environmental Change, 58, 101947.

Richter, I., Thøgersen, J., \& Klöckner, C. (2018). A social norms intervention going wrong: Boomerang effects from descriptive norms information. Sustainability, 10(8), 2848. doi:10.3390/su10082848 
Rustagi, D., Engel, S., \& Kosfeld, M. (2010). Conditional cooperation and costly monitoring explain success in forst commons management. Science, 330(6006), 961-965. doi:10.1126/science.1193833

Schultz, P. W., Nolan, J. M., Cialdini, R. B., Goldstein, N. J., \& Griskevicius, V. (2007). The constructive, destructive, and reconstructive power of social norms. Psychological Science, 18(5), 429-434. doi:10.1111/j.1467-9280.2007.01917.x

Sellmann, D., \& Bogner, F. X. (2013). Effects of a 1-day environmental education intervention on environmental attitudes and connectedness with nature. European Journal of Psychology of Education, 28(3), 1077-1086. doi:10.1007/s10212-012-01550

Shearer, L., Gatersleben, B., Morse, S., Smyth, M., \& Hunt, S. (2017). A problem unstuck? Evaluating the effectiveness of sticker prompts for encouraging household food waste recycling behaviour. Waste Management, 60, 164-172. doi:10.1016/j.wasman.2016.09.036

Spada, H. \& Opwis, K. (1985). Ökologisches Handeln im Konflikt: Die Allmende-Klemme. In P. Day, U. Fuhrer \& U. Laucken (Hrsg.), Umwelt und Handeln (S. 63-85). Tübingen: Attempto.

Spada, H., Opwis, K., Donnen, J., Schwiersch, M., Ernst, A. (1987). Ecological knowledge: Acquisition and use in problem solving and in decision making. International Journal of Educational Research, 11, 665-685.

Steg, L., \& Vlek, C. (2009). Encouraging pro-environmental behaviour: An integrative review and research agenda. Journal of Environmental Psychology, 29(3), 309-317. doi:10.1016/j.jenvp.2008.10.004 
Stern, P. C., Dietz, T., Abel, T., Guagnano, G. A., \& Kalof, L. (1999). A Value-Belief-Norm Theory of support for social movements: The case of environmentalism. Human Ecology Review, 6, 81-97.

Sussman, R., Greeno, M., Gifford, R., \& Scannell, L. (2013). The effectiveness of models and prompts on waste diversion: A field experiment on composting by cafeteria patrons. Journal of Applied Social Psychology, 43(1), 24-34. doi:10.1111/j.15591816.2012.00978.x

Stevenson, K. T., Peterson, M. N., Bondell, H. D., Mertig, A. G., \& Moore, S. E. (2013). Environmental, institutional, and demographic predictors of environmental literacy among middle school children. PloS one, 8(3), e59519. doi:10.1371/journal.pone.0059519

Tobias, R. (2009). Changing behavior by memory aids: A social psychological model of prospective memory and habit development tested with dynamic field data. Psychological Review, 116(2), 408-438. doi:10.1037/a0015512

Tucker, R., \& Izadpanahi, P. (2017). Live green, think green: Sustainable school architecture and children's environmental attitudes and behaviors. Journal of Environmental Psychology, 51, 209-216. doi:10.1016/j.jenvp.2017.04.003

van Vugt (2001). Community identification moderating the impact of financial incentives in a natural social dilemma: Water conservation. Personality and Social Psychology Bulletin, 27, 1440-1449.

van Vugt, M. (2009). Averting the tragedy of the commons: Using social psychology science to protect the environment. Current Directions in Psychological Science, 18, 169-173. Vaughan, C., Gack, J., Solorazano, H., \& Ray, R. (2003). The Effect of Environmental Education on Schoolchildren, Their Parents, and Community Members: A Study of Intergenerational and Intercommunity Learning. The Journal of Environmental Education, 34(3), 12-21. doi:10.1080/00958960309603489 
Yates, S. M., \& Aronson, E. (1983). A social psychological perspective on energy conservation in residential buildings. American Psychologist, 38(4), 435-444. doi:10.1037/0003-066X.38.4.435

Zelezny, L. C. (1999). Educational interventions that improve environmental behaviors: A meta-analysis. The Journal of Environmental Education, 31(1), 5-14. doi:10.1080/00958969909598627

\#FridaysForFuture (2019). Retrieved September 27th 2019, from https://fridaysforfuture.org/ 
Appendix A

Table 1

Correlations (Pearson) between sustainability measures with regard to the group performance.

Intervention

Positive model Control

\begin{tabular}{llcccc} 
& & Replenishment & Final Stock & Replenishment & Final Stock \\
\hline Before & Rounds & $.68^{* *}$ & $.43^{* *}$ & $.58^{* *}$ & $.49^{* *}$ \\
& Final Stock & $.71^{* *}$ & & $.91^{* *}$ & \\
After & Rounds & $.29^{*}$ & $.39 * *$ & $.57^{* *}$ & $.36^{* *}$ \\
& Final Stock & $.78^{* *}$ & & $.80^{* *}$ & \\
\hline
\end{tabular}

Note. ${ }^{*} p<.01,{ }^{*} p<.05 . n=66$ per intervention condition. 


\section{Appendix B}

Text of the role model condition. "This is a story about two foresters, Peter and Franz. Together they own a forest, which is not particularly huge but contains enough trees, so that the two can assure their livelihoods and earn enough money for their families by logging trees to sell firewood. In order to ensure the continuity of the forest, Peter and Franz do not only cut trees but also regularly plant young new trees. One day, Franz decides that he wants to build a new house and therefore needs to log more trees to earn more money. Peter issues a warning and reminds him of the limited capacities of the forest. He tells Franz that not too many trees should be logged to ensure that the young trees have enough time to grow so that the size of the forest is stable. But Franz ignores the warning and starts to cut twice as many trees as before. Even though Peter continues with his strategy of only cutting a few trees to protect the size of the forest, it starts to get blank. Some time passes and one day when entering the forest, Franz is deeply shocked by its bleakness. He realizes that there are nearly no big trees left and he understands that Peter was right, and he himself logged way too many trees so that there was not enough time for the young trees to grow and fill the gaps. If he would continue cutting down so many trees, soon there wouldn't be a single tree left in the forest.

Consequently, they won't be able to produce firewood and earn money for their families anymore. Franz is glad about Peter realizing finally that the forest will only survive in the future if they use a moderate, sustainable strategy of logging trees in the present. These considerations lead to Franz's decision to follow Peter's example and resume to the strategy of only cutting a few trees. This allows Peter and Franz to assure their livelihoods by selling firewood even in the distant feature."

Text of the control condition. "Homegrown vegetables, fresh herbs and colorful flowers: In the cities, more and more people get feel like gardening. This desire started a new trend which is called urban gardening. It describes the horticultural use of public areas within a city. 
Instead of belonging to private people public areas are owned by the city itself. Roofs, grass verges, walls next to the police station or areas right in the city center - everything can be used for gardening. Even though urban gardening is a big trend now, the idea is actually based on a really old concept. Looking back to the mediaeval times or the antique, one can already see small gardens and fields as regular part of any city. If people are asked about their reasons for urban gardening, the answers are manifold. Some do it to beautify the city, others hope to save money and still others simply want to learn about gardening and don't have other possibilities in the city available. As a part of urban gardening, another movement arose - it is called „Guerilla Gardening“, which means something like “warlike gardening”. The Guerillas are fighting for a more beautiful city and use seed bombs as their weapons. These seed bombs, filled with lots of different flower seeds are thrown on empty and neglected areas in the cities, which leads to their transformation to a beautiful sea of flowers. Despite the visual beauty of the action, it also contains a political impeachment. The participants want to rivet on the governmental neglect to beautify the empty areas within the cities which forced the guerillas to become active themselves. The is a wide range of projects and it will increase in the next years, since there is plenty of space and possibilities in every city. So, don't be surprised if shortly you see pumpkins, heads of lettuce or tomatoes growing right in the city center." 